\title{
Invited Commentary: Seeking a Coherent Strategy in our Response to Homeless and Street-Involved Youth: A Historical Review and Suggested Future Directions
}

\author{
Sean Kidd
}

Received: 20 December 2011/ Accepted: 13 January 2012/Published online: 1 February 2012

(C) Springer Science+Business Media, LLC 2012

\begin{abstract}
This invited commentary seeks to encourage a critical dialogue about youth homelessness that might assist in re-energizing a field that seems increasingly stagnant with a research body focused primarily on analyses of risk, hopelessly inadequate policy frameworks in most cities, diminishing funds for services, and decreasing media attention. Reviewing major trends in research and public responses to youth homelessness in the past century, I propose that there exist three major culturally-bound dimensions from which we construct our understanding of and responses to youth homelessness. These dimensions, which are considered in a transactional framework, are the scope of responsibility, the location of moral responsibility, and the amount of agency attributed to the youth. In this review I highlight the manner in which our historically binary and uncritical understanding of these dimensional characterizations of youth homelessness has led to major lapses in the effectiveness of our collective efforts to address this problem. I highlight gaps in the existing body of research literature and provide this framework, arguing that a strategic and cohesive response is vital if we are to move from reiterations of risk and hackneyed calls for prevention strategies to the generation of meaningful solutions.
\end{abstract}

Keywords Homeless youth - Street youth - Review . Policy · Intervention · Prevention

S. Kidd $(\bowtie)$

Department of Psychiatry, University of Toronto,

Toronto, ON, Canada

e-mail: sean_kidd@camh.net
In considering the current context of our responses to youth homelessness, two recent conversations come to mind. Both were with friends who manage services for homeless youth in Toronto, Ontario. In one, the director of a service for sex trade involved youth spoke with me about their difficulty engaging youth in recent years due to very few using strolls for transactions where they can be approached by outreach workers. Most are now using the internet to arrange tricks in a manner that makes it nearly impossible to make service-related contacts with them. This organization had been a fixture of the service provision community in Toronto for over 25 years and one of the highest profile services (in 1998 the band Smashing Pumpkins donated the entire revenue of a Toronto concert to them). It closed its doors in August, 2011 as its parent organization no longer considered it a feasible and sustainable service model. In the other conversation, a manager of a busy comprehensive drop in service for street-entrenched traveler youth, and the only such service in the city, was telling me about her plans for early retirement after their board decided to close the service in the spring of 2012 due to funding problems and the parent organization rethinking its larger mission. Similar to the first, this service has a very high profile in the city and is often placed in the forefront of the parent organization's fundraising campaigns.

The subtext to both of these conversations was essentially a question about what exactly our collective response is or should be for this population or, more accurately, these populations of young people living out a range of existences on the streets of North American urban centers. Having been involved in the field in a range of capacities since the 1990s, including research, clinical work, advocacy, and service organization leadership, I find the field in desperate need of a coherent framework bridging across research, service, and policy domains. Conversations such 
as those noted above are increasingly common across stakeholder groups as providers, researchers, policy makers, and youth themselves observe social and financial resources fragmenting and diminishing while the problems that they are facing steadily increase.

This commentary was written to encourage a critical dialogue about youth homelessness that might assist in reenergizing a field that seems increasingly stagnant with a research body focused primarily on analyses of risk, hopelessly inadequate policy frameworks in most cities, diminishing funds for services, and decreasing media attention. This issue is just as important as it was 20 years ago, when media and research attention to the issue dramatically increased (Kidd and Taub 2004). As Elise Roy and colleagues have recently pointed out (Roy et al. 2010), there continues to be large numbers of youth on North American streets whose mental and physical health are deteriorating and who are dying at a rate several times that of their housed peers.

\section{Youth Homelessness: A Snapshot}

It has been extremely difficult to characterize young people whose unstable and impoverished living circumstances have left them living on or spending large amounts of time on the streets or who are otherwise disengaged from social institutions and ways and places of living that are congruent with mainstream cultural values. Nonetheless, there is a general belief in Western contexts that these young people represent a distinct population and there are services and policies directed towards them. The ambiguity surrounding their description begins with the terms used. The term "runaway" was commonly used up to the 1980s, although has since been supplanted, possibly due to increased acknowledgment that nearly half of these young people were in fact thrown out of their homes and might be more accurately characterized as "throwaways" (Adams et al. 1985). "Homeless youth" is a term often applied, although is often substituted with "street youth" or "streetinvolved youth" since many of these young people do not fall under the definition of homelessness as being people who lack shelter or live "rough". Accurate definitions are further confounded by the differing age ranges that are applied, ranging from low age cutoffs of 12 with high age cutoffs of 24 and in some service sectors even higher. This ambiguity around the description compounds the already difficult task of obtaining accurate estimates as to the number of homeless youth. The only agreed upon points regarding the number of homeless youth in North America is that it is large (e.g., 1 million youth in the United States; Kidd and Scrimenti 2004) and it is likely growing (U.S. Conference of Mayors 2010). For the purposes of this commentary I will use the term "homeless youth" in a manner intended to be inclusive of youth who are both living out of doors or otherwise lacking adequate stable housing with appropriate shelter and amenities (U.S. Department of Education 1989).

Aside from a general agreement that there are large numbers of homeless youths on North American streets and those numbers are likely growing, the only other relatively unambiguous fact is that the health trajectories of most homeless youth are poor and mortality rates are strikingly higher than those of housed youth. Though highly variable, estimates of up to 40 times the mortality rate of housed youths have been observed (Shaw and Dorling 1998) with primary causes of death identified as suicide and drug overdose (Roy et al. 2004). It is also clear that youth homelessness has been seen as a social concern requiring study and intervention with the earliest references to this stance dating from the Colonial period in North America (Kidd and Taub 2004).

Growing from this large, albeit poorly defined, population that requires intervention due to high levels of physical and mental health risks are a wide range of conceptualizations and responses. In this commentary we propose to examine three major culturally-bound dimensions from which we construct our understanding of and responses to youth homelessness. The three interrelated dimensions that would seem to determine how we understand youth homelessness are the scope of responsibility, the location of moral responsibility, and the amount of agency held by the youth. These three dimensions that frame how we construct youth homelessness in turn drive our responses-be it the direction of inquiry through research or intervention. Across these three dimensions are ongoing interactions with sociocultural contexts, the responses generated, and the youths who are the subject of this scrutiny. I intend to trace these patterns, referencing key articles, and highlighting the manner in which our historically binary and uncritical understanding of these dimensional characterizations of youth homelessness has led to major lapses in the effectiveness of our collective efforts to address this problem. I propose that there is a compelling need to use frameworks such as the one proposed here to conceptualize research, policy, and service responses if we intend to generate coordinated and effective solutions. I argue that a coordinated strategy is needed due to the one other clear fact about homeless and street-involved youth that would seem evident: there is every indication that contemporary social responses are failing.

\section{The Scope of Responsibility}

Understanding of the scope of responsibility for youth homelessness can be conceptualized as a dimension. It has 
macroeconomic and systemic explanations on one end, parental responsibility somewhere in the middle, and individual explanations at the other extreme. While there is often some superficial commentary about the need to attend to the full spectrum and at any given time there are exceptions to predominant trends, historically there have tended to exist movements characterized by totalistic explanations. In the 1910s-1930s, youth homelessness was considered by most researchers to be due to individual deficiency, often in the form of some form of fundamental pathology or genetic defect (Burt 1923; Furnald 1912; Gilpin 1930; McIver 1927; Riemer 1940; Thomas and Gostwyck 1925; Weidensall 1913). Running away was attributed to the child's inability to perform in school, control their instincts, and learn social and moral functioning. The etiology of these problems, in line with the then popular eugenicist framework, was in many commentaries associated with the "subnormal" parents of such youths (McIver 1927). Close attention was paid to physical features with some studies highlighting characteristics such as "thick lips" and "ears outstanding" (e.g., Furnald 1912).

In the 1930s and 1940s, conceptualizations of youth homelessness shifted away from individual-level explanations to an emphasis on macroeconomic factors. This shift coincided with the Great Depression, the social impacts of which could hardly be ignored as it became impossible to explain behaviors such as running away without attending to social and economic influences. Authors commented upon the large numbers of children and youth leaving due to extreme poverty and the family problems stemming from poverty (Abbott 1933; Levy 1933; Newcomb 1933; Outland 1938). Many of these authors made the argument that running away was a normal reaction to abnormal circumstances.

From the late 1940s to the late 1960s the number of publications on youth homelessness markedly decreased (Kidd and Taub 2004), but what is evident in the small number of publications that exist is a return to individuallevel explanations. Psychopathology once again became the emphasis (Leventhal 1964; Robins and O'Neal 1959; Wattenberg 1956); a perspective exemplified by the inclusion of the "runaway reaction" in the Diagnostic and Statistical Manual of Mental Disorders-II (DSM-II) (Jenkins 1971). For the next shift to macro-level explanations the cause would seem to have been cultural rather than economic. The counterculture movement of the mid-1960s to the early-1970s was associated with an increasing public recognition of youth homelessness and large numbers of youths travelling. Several works appeared that examined runaway behavior in the light of dissatisfaction with the "the establishment" that was the cultural norm for many youths at the time (i.e., rejection and abandonment of mainstream values and beliefs) (e.g., Adams and Munro
1979). Not only was public attention drawn to runaways, but in 1974 the United States federal government's implementation of the Runaway Youth Act and decriminalization of running away brought increased legislative attention and funding (Libertoff 1980).

The late 1980s saw a large increase in the number of articles addressing youth homelessness, likely as a function of both the increasing number of journals and increasing attention to the topic (Kidd and Taub 2004). In this time and into the 1990s, the predominant perspective once again retreated from macro-level explanation to one involving abuse and instability amongst families of origin. Research focused largely on high incidences of physical and sexual abuse and neglect in home and emphasized general histories of dysfunction and instability including frequent reports of domestic violence, parental criminality and substance abuse, poverty, frequent moves and changes of school (Dadds et al. 1993; Maclean et al. 1999; Molnar et al. 1998; Ringwalt et al. 1998). While abusive and chaotic home environments had received some peripheral attention previously (e.g., Gilpin 1930), this was the first time such an explanation came to the forefront. It was a shift reflected at the service provider level as well with, for example, one service reporting a threefold increase in the number of reports of abuse by youth in just 2 years in the 1980s (New York Times 1988).

The current context is somewhat less clear. The research literature has at least to some extent moved on from the large wave of studies that use self-report histories to examine abusive homes as being the cause of homelessness and correlating abuse with street trajectories. Though it should be noted that, despite the glut of studies using this approach, there can still be found articles focusing on rates of pre-street abuse. The decline in articles and commentary emphasizing abuse and neglect in a totalistic way and increase in attention to mental illness and substance abuse may suggest that the current understanding has moved to some degree towards an individual explanation. However, it is clear that other than brief reference, macro-level explanations of homelessness receive little attention and history would suggest that it takes large-scale economic and cultural shifts to prompt thinking in this direction.

Though public perspectives are more difficult to examine systematically than the research literature it would seem, with a few exceptions, to follow in an approximate manner that of the trends in research with respect to explanations. If coverage of youth homelessness in the New York Times might be taken as a sociocultural barometer, there are emphases upon large scale social factors in the Great Depression (New York Times 1932) and Countercultural Revolution (New York Times 1968) and abuse in family contexts in the 1980s (New York Times 1988). Though it is noteworthy that this latter commentary had at least a nod to macro-level factors in the 
consideration of the impact of crack and AIDS epidemics in low-income neighborhoods in the 1980s and early 1990s (Gershenson 1998).

\section{The Location of Moral Responsibility}

The location of moral responsibility is the second dimension. It is one in which moral responsibility is situated solely with the youth at one extreme and at the other extreme situated solely as being that of larger society. While clearly intertwined with understandings of at what level responsibility for their homeless circumstances lie (Minkler 1999), the moral overlay of blame and responsibility play a key role in determining the type of response that is needed and who should be responding. The mid-1800s through to the late 1910s represented something of a paradox regarding youth homelessness and morality. The Social Reformers and Progressives of this period, in many ways, located the moral responsibility for the problems of youth (including poverty, poor health, and crime), as being one of larger society. These sociopolitical movements, which extended up to World War I, emerged in large part to address the inequities of the Capitalist system (Tallack 1991). It was thought that, through the leadership of "enlightened" individuals, a program of social control could be implemented that would result in improved morality and respect for cultural standards (Burnham 1988). Through this moral agenda, the Social Reformers and then Progressives contributed enormously to the undertaking of addressing the deplorable conditions of the prisons and orphanages in which vagrant children were placed. These were settings in which most youths were severely malnourished, with one-eighth of them dying of disease and many going blind due to opthalmia (communicable eye infection) (Folks 1900/1971). The paradox, from the moral perspective, of these movements is that while they located moral responsibility in larger society, they were also responsible for the criminalization of running away and the creation of juvenile courts and the concept of "delinquency", which in many ways apply a moral explanation at an individual level (Libertoff 1980; Mennel 1973). Much of the research in this period applied an overt moral explanation of youth homelessness, albeit one that did not acknowledge the larger social morality concerns of the political movements described above. Investigators examined and commented on evidence of moral "degeneracy", framed as an inadequate development due to poor genetic "stock" or other factors (e.g., Furnald 1912; Swift 1909).

From this point forward, morality, in most formal commentary, became implicit rather than directly applied. First, there is a moral implication to the criminalization of youth homelessness just as there has always existed, if in a problematized way, the link between law and morality (Raz
2009). From the vagrancy and truancy laws of the early twentieth century to the current wave of "Safe Streets" legislations enacted in the past 20 years in North American Cities (O'Grady and Greene 2003), the criminalization of youth homelessness in a de facto manner implies that they are morally responsible for their circumstances and require correction. While this underlying moral implication has been consistently present, the trends in attributing responsibility likewise affect the moral stances taken. During the great depression, commentary in both public forums (New York Times 1932) and research commentary (Newcomb 1933) suggests that moral responsibility shifted to that of larger society with youth seen as victims of circumstances out of their control. From that point on, the question of morality entered into a period of flux. In the 1950s and early 1960s, the application of models of psychopathology in some ways abdicates all moral responsibility as homelessness becomes a symptom of a mental illness (Leventhal 1964; Wattenberg 1956). While the impact of the Counter Culture revolution is unclear, other than to suggest that larger sociocultural forces were responsible for homelessness, it is clear that the wave of abuse explanations that emerged in the 1980s and 1990s placed moral responsibility squarely upon the shoulders of parents.

Currently, in the absence of the more totalistic perspective about abusive parents, the undertone of criminality would seem to be coming to the forefront. This has been heightened with the tremendous increase in the criminalization of behaviours associated with youth homelessness, such as vagrancy and pan handling. Such legislation has appeared with increasing frequency and intensity in defining infractions and punishments in most North American cities in the past 15 years (e.g., New York City general city law $\$ 39.20$, penal law $\$ 240.80$; Statutes of Ontario, c. 8, 1999). Other threads pertinent to morality, though again only by implication, include increasing dialogue regarding mental illness and addictions, which in many senses abdicates morality and the decreasing funding for services for homeless youth in many cities, which would seem to suggest an abdication of a social-level moral responsibility for generating solutions.

\section{Youth Agency}

The third dimension is one involving the agency ascribed to the youth with one extreme being youth seen as completely free and active agents in determining their life trajectories and the other extreme involving their being completely passive victims of their circumstances. As with the moral dimension, attributions of youth agency are held against the ongoing backdrop of criminality, which holds the implication that youths are active agents in their 
circumstances and need to be held accountable for their choices-whether it be choices that lead to their simply having to live on the streets or the "choice" to pan handle as a source of income. This notion of active agency also aligns with the adventure-seeking explanations of youth homelessness. In both the early twentieth century and in the Counter Culture period, the idea of adventure seeking was prevalent in popular accounts of youth homelessness. In the early twentieth century, media commentary carried frequent articles that carried a light-hearted and in some instances comedic tone such as a "plan to emulate wild west heroes" (New York Times 1931, p. N3). Though in the Counter Culture period the commentary suggested that while it was believed that youths demonstrated agency in leaving home, in many instances they lost it once the superficial aspects of the adventure were over and they found themselves in environments in which their health deteriorated and they were victimized by a range of predators (Adams and Munro 1979; New York Times 1968).

The other extreme of this dimension, that of youths' being passive victims of circumstance, is reflected in the wave of abuse explanations that emerged in the 1980s and 1990s as well as in the majority of the research literature. As has been discussed earlier, the emphasis upon parental abuse, neglect, and instability suggests that youths end up homeless without any real choice in the matter. With respect to the majority of the research commentary, authors have consistently portrayed youth as being largely passive in the process of becoming homeless and their homeless trajectories. This emerges in both the content of studies of the etiology of youth homelessness (e.g., mental or genetic defect, economic or cultural upheaval, psychopathology, parental abuse) and the methods used in more contemporary risk factor analyses in which youths are implicitly placed in the position of billiard balls passively knocked into various street risk trajectories as a function of previous risk exposure. The line of research that is an exception in its examining the more active roles of homeless youth in surviving and prevailing over their circumstances is the resilience literature that has emerged in the past 15 years (Kidd 2003; Kidd and Davidson 2007; Lindsay et al. 2000; Rew and Horner 2003; Williams et al. 2001). These studies emphasize factors such as youths' cultivation of strategies to support self-reliance, spirituality, and the processes through which they seek to adapt to their shifting circumstances as they navigate street and non-street contexts and cultures.

\section{Transactions with the Homeless Youth}

Interacting with each of these dimensions of level of responsibility, morality, and agency, is the individual youth's trajectory over time-their lives before coming to the streets, on the streets, and afterwards. Over the course of their trajectories, they might occupy many sociocultural positions, conceptualize themselves and be conceptualized in multiple positions across the above three spectrums, and have different types of transactions with society as a function of these social, cultural, and individual meeting points. Indeed, it would seem sensible to consider the youths' relationship with these sociocultural conceptualizations within a transactional model-one in which the youth affects the context and the context affects the youth (Sameroff 2009). A given youth might run away from a group home having internalized years of negative messages about herself, as a loser who deserves bullying, as a stupid person who doesn't do well in school, as a failure whose own parents do not want her. Once on the streets and labeled street youth she might interact with service providers that reframe her circumstances as one of her being the victim of abuse, neglect, and a failed school system. Her exploring that narrative with her peers might then lead to some mockery of her acting out the stereotype of the helpless abused homeless girl—something that I have frequently overheard in conversations among youth. They might encourage her to take a more active role in her survival, one that requires a collective rather than individual response with action needed at a political level to react to their being discriminated against by the public, police, and other social institutions.

Other systems will in turn react to her transformations. Her acting out an understanding of her circumstances as a victim of abusive and discriminatory environments will likely garner her more sympathy and support in interactions with non-street involved persons such as service providers and the public. Her acting out a more defiant and politicized stance regarding her circumstances may lead to greater status with her peers but more conflict with authorities and a reinforcement of perceptions that her circumstances are her responsibility, morally and otherwise. All of these types of transactions, in turn, are situated in the ebb and flow of the larger cultural context in which factors such as social upheavals like the Great Depression, criminalizing legislation, or theoretical frameworks like eugenic or psychoanalytic theories that influence perspectives and communication. While clearly larger sociocultural factors have a tremendous impact on youth ranging from provision of services, imprisonment, and public response, it is also likely the case that youths themselves can impact larger social narratives. A high profile death by suicide (Saul 2002) might sway public opinion in the direction of understanding youths as passive victims while "exposés" of youth exaggerating the extremity of their circumstances (Buiso and Giove 2011) or a story of a squeegee kid assaulting a driver (Switzer 2011) might lead to an emphasis on individual responsibility. 


\section{The Current Scenario}

In some ways, at present we would seem to be in a time of regarding youth homelessness, in terms of responsibility, moral and otherwise, as being at the individual level. We have increased criminalization, which implies individual responsibility morally and otherwise and suggests agency on the part of youths in their making choices to contravene these restrictive legislations. This coincides with the rolling back of the totalistic explanations of child maltreatment as the cause of homelessness. At the same time, the research literature seems to be in an undetermined phase. The crosssectional risk factor research is diminishing, likely due to there being little more to add to the existing knowledge base and the tremendous difficulty of using longitudinal designs (though some have had success in this area-e.g., Slesnick et al. 2008; Tucker et al. 2011) that might enhance and expand this line of inquiry. An individual level focus and a return to earlier lenses of psychopathology that deemphasizes agency are arguably on the rise in the form of the medical-model emphasis on randomized trials and symptom/problem-specific interventions. This is a framework that is increasingly appearing in homeless youth research and service provision contexts. These turns towards individualistic explanations somehow seem to be largely impervious to the socioeconomic changes in recent years in the form of a major economic recession. It is hard to imagine that the rapid rise in poverty and unemployment at the family level is not impacting the rates of youth homelessness and that the decreasing service sector budgets and closures are not effecting trajectories of youth on the streets. From the research perspective, it would seem likely that a part of the reason that larger social factors get relegated, at best, to an anecdotal statement in discussion sections is that they are so very difficult to study. Taking an anecdote from a talk I regularly give on youth homelessness, one might imagine a pattern such as this:

"While even in the best of circumstances it is safe to say that neglect and abuse will occur in family contexts that will lead to youths' being homeless, the impact of poverty can't be understated. Take for example the uncle who in better times might never have acted on his mild predilection towards the sexual abuse of minors. He has, however, became unemployed, had severe marital stress, greatly increased his alcohol consumption, and has been spending more and more time at his sister's house. There he is left alone with his niece quite often and he molests her. The mother is single and, having lost her full time job, spends much of her time juggling part time positions to make ends meet, is exhausted and stressed, and does not notice the signs of abuse.
She might also be dismissive of the indirect complaints of her daughter as yet another problem that she can't manage. The daughter runs away from home."

One might imagine hundreds of iterations of this kind of scenario, all of which have the commonalities of being driven by poverty and being extremely difficult to capture in research. These stories also embody the kinds of complex interactions of risks and social determinants of health that make for poor news stories, which tend to favor clear unicausal explanations: Dad beats up his son-his son runs away. Girl is a junkie and a prostitute who is lowering our property values and is complaining of poverty while she uses an expensive cell phone. It is clear, however, that there is a striking lack of acknowledgement of larger social factors in our existing frameworks of public discourse and research.

\section{The Importance of a Cultural Analysis in Youth Wellness and Social Response}

I believe that the importance of critical type of analysis that I am proposing lies in its implications for the health and wellbeing of youth affected by homelessness and our collective responses from service delivery models to public perceptions. The utility of such a theoretical analysis lies in its ability to sidestep some of the problems that would seem to underlie the inadequacy of our efforts to date. These problems include the endemic difficulties in researching complex social behavior, which include a tendency to employ individual-level theories of behavior which are reified by study designs (Fisher et al. 1986). This, in turn, helps drive the "person-blame attribution bias" that involves a one-sided blaming of victims for their personal and social problems (Caplan and Nelson 1973; Sampson 1977). The other major problem that seems to have plagued much of the study and understanding of youth homelessness to date is the well-documented tendency of people favouring unicausal explanations even when there is a large amount of evidence indicating multicausality (Nisbett and Ross 1980).

The impacts of these biases in the lives of youth are profound. When explanations are individualistic, moral responsibility is social, and youth are passive victims, we seem to trend towards wanting to treat them for psychopathology. When explanations and moral responsibility are individualistic and youth are active agents, we arrest them and put resources into policing and correctional services. When explanations and moral responsibility trend towards a macro societal level, we see large scale social interventions such as those embodied in Roosevelt's New Deal of 
the 1930's (Watkins 1993) and the creation of the Runaway Youth Act in 1974 (Libertoff 1980). The emphasis on familial abuse and neglect with youth as passive victims would seem to have led to an increase in the support of social services for homeless youth. These turns would seem to affect youths directly as well. There are indications that when youths frame their circumstances through the lens of social oppression and discrimination they are more resilient in the face of stigma as they are better able to frame discrimination at a social rather than an individual level (Kidd 2007; Kidd and Davidson 2007). Youth also would seem to readily take up mainstream messages, as seen in the extremely rapid rise of reports of familial abuse among homeless youth in the 1980s (New York Times 1988). There is also a sense of oppression among youth in response to the passive victim explanations for their circumstances. While some might at times portray themselves as the "helpless shivering waif" (as one youth described it to me) to garner support from non street-involved persons, many will communicate a rejection of this disempowering identity among themselves (Kidd and Davidson 2007).

The research endeavor, taken as a whole, has generally been inadequate and has not employed the tools necessary to have a meaningful impact in youths' lives. As authors have been commenting for many years (e.g., Fisher et al. 1986), we continue to apply individual level and otherwise constrained models of inquiry that cloud our understanding of complex social phenomena. Furthermore, our collective perseveration on describing risk depletes resources that need to focus on generating solutions-research into which is highly circumscribed. Indeed, this might be a circumstance for an improved recognition that for some social problems the scientific paradigm of inquiry can only make a very modest contribution and waiting for "answers" from this quarter will only delay a much-needed response. A striking example of this need is the implementation of prevention strategies. Researchers have for so long been ending articles with calls for research into prevention efforts that it is beginning to resemble a "rain dance" approach to the problem-if we ask for it enough times maybe some day it will magically happen. Indeed, if one was to apply the moral lens to researchers, a case might be made that the research endeavor to some extent is an extension of the exploitation of these young people. The exaggeration of the promise of solutions while, consciously or not, employing inadequate research models lacking discernable strategy leads to false promises to youth that their participation can be expected to lead to solutions and a complicity with the inertia surrounding a social response as policy makers wait for researchers to provide direction. Returning to our few objective facts about homeless youth, that their numbers are increasing and that their health steadily diminishes and many die from their circumstances, we need to consider rejecting as unethical studies that use increasingly scarce resources to provide yet another description of risk and another bland and meaningless suggestion for improved prevention efforts.

\section{The Need for Balance and Strategy}

What would seem needed at this point is a clear and unified strategy to address youth homelessness effectively. There are clearly problems with unicausal explanations for youth homelessness, both in terms of accuracy and the very limited responses that grow from them. We need to advocate, both in the form of individual advocacy and the use of existing vehicles (e.g., World Health Organization, National Institutes of Health, Canadian Institutes for Health Research), for targeted research inquiry and the development of best practices from policy to front line intervention. The utility of this type of framework lies in it facilitating a balanced perspective on youth homelessness-one that resists a seemingly natural slippage into unicausal or totalistic explanations and responses. Examples of areas that need to be addressed through an integrated and strategic approach include the following.

\section{Macro Level}

If there existed a substantive body of research linking macro-level factors with youth homelessness, it would assist in both improving the recognition that youth homelessness is in many instances a symptom of more fundamental social problems and would provide motivation for larger social responses. An example of a study that could assist in addressing this question would be one in which all high schools in a given city or cities surveyed staff regarding incidents of homelessness in a given year and these data were referenced against neighborhood-level socioeconomic characteristics. If such macro-level models of inquiry were to enter the homeless youth discourse it might reduce the marginality of the population, placing them within a problematic socioeconomic system in which we are all involved and for which we all have some responsibility.

\section{Prevention: Service Level}

To assist in moving inquiry into prevention beyond rhetoric, inquiry could target the three types of institutions that have the most contact with youth before they become homeless: child protection, criminal justice, and education. For example, one might examine the impacts of policy, 
procedures, and interventions linked with youths leaving child protection and criminal justice systems. For schools, some forms of prevention likely do not require new research. There already exist evidence-based strategies designed to address factors such as bullying in schools (e.g., Vreeman and Carroll 2007). Given that such factors common to the backgrounds of many homeless youth they could in fact be framed as prevention efforts with homelessness being added to the evaluation of their impacts (recognizing that the low base rates of homelessness will pose a challenge to statistical investigation). As the interest in generating pathways for "transitional aged youth" and the creation of early intervention services increases in many sectors, particularly healthcare, providers and researchers might readily find support for implementing and evaluating service models that reduce the number of youth who end up homeless.

\section{Intervention: Service Level}

Taken in isolation, randomized trials of individual-level interventions carry the risk of neglecting systemic factors and youth agency. They are, however, essential to a strategic approach to addressing youth homelessness. With very few exceptions (e.g., Slesnick et al. 2008; Slesnick and Kang 2008), the effectiveness of interventions with homeless youth have not been examined. We need a better understanding of intervention effectiveness and the service structures in which combinations of interventions are assembled. There arguably exist many extremely effective services and programs, with some incorporating broad well-networked strategies that align with the arguments of this commentary. The difficulty is, with very few exceptions (e.g., Walsh and Donaldson 2010), such models of care are not being articulated, studied, or disseminated. This is particularly the case for prevention and intervention strategies that are community-based and not a part of formal service structures. These interventions, which might be considered in many ways forms of social entrepreneurship, are even further marginalized from mainstream service and research dialogues (Kidd and McKenzie in press). Undertaking a more systematic study of service models would not only provide opportunities to propagate more effective interventions, it would also allow for a systematic study of the economic impacts of these programs. This would be of great help in improving the resourcing of service organizations. As compelling as Covenant House advertisements can be with a destitute youth huddled under a credit card we are in an economic climate that seems to be increasingly one in which "feel good" types of appeals have less and less traction.

\section{Criminalization}

Given the expense of policing "safe streets" legislation and incarcerating homeless youth and the many potential spin off effects of criminal conceptualizations upon moral attribution, there is a compelling need for the study of how criminalization impacts youth trajectories. If, for example, criminalization was found to breed further criminalization and longer street careers, the costs would be outweighing the benefits of providing resources to other forms of intervention. This would be greatly facilitated if such inquiry was integrated with the development of evidence based models of care as described above. One can only imagine that the lack of systematic inquiry in this area is facilitating ill-informed policy responses and leaving gaps filled by poorly researched explanations. A case in point might be the extremely popular book of Malcolm Gladwell (2002), The Tipping Point, in which he makes a compelling if loosely reasoned argument that arrests for offences such as pan handling and squeegeeing have a sort of "butterfly effect" on all other types of criminality.

\section{The Elephant in the Room}

In all of the existing inquiry into youth homelessness, with the exception of some of the coverage of the impacts of the Counterculture period, there is virtually no accounting for why youths from supportive homes with access to adequate resources become homeless. In a risk-centric research literature, we have collectively forgotten about the other half of the distribution. Arguably, about half of the youths who are homeless at any given time came from environments where they were neither abused nor neglected. There would seem to be a benefit in developing a better understanding of these youths and how interventions might be targeted to better address their specific needs and relative wealth of resources. Indeed, this point speaks to the larger need, as intervention research progresses, to develop a typology of homeless youths that will be of diagnostic use in targeting interventions given the radical differences between subgroups (e.g., Martino et al. 2011).

\section{Where Do They End Up?}

Likely a function of the challenges of longitudinal research with this population, this important question remains largely unanswered. Some die on the streets while others no doubt become chronically homeless into adulthood. Some enter into lives of housed poverty and instability and others become professionals with good incomes. We have no idea, however, of the proportions or determinants across 
these categories. Even the most informed providers have difficulties with this question since most youth "disappear" from their services for any number of reasons, though they can readily provide anecdotes about individual youth who fall into each of the above categories. In an integrated program of research, we would understand the factors involved with each of these trajectories and determine if some of these factors are amenable to intervention. The development of "postvention" best practices would likely be of great assistance in reducing the number of youth who return to homelessness and reducing their commencing on housed lives that are a lifelong reflection of the risks and deprivations faced as children and adolescents. The need for such strategies has been highlighted, albeit in the homeless context, wherein it has been found that the benefits of homeless youth services are poorly maintained once contact with the service ends (Pollio et al. 2006).

\section{Putting a Strategic Response into Practice}

A general propagation of a framework for responding to youth homelessness could be of some help in this context. It could potentially guide individual researchers and policy makers in bringing conscious attention to their blind spots, guide grant review committees, and possibly prompt targeted calls for research programs. What would be far more advantageous, however, would be the development of institutes or commissions that have strong connections with policy makers at all levels, strong public relations and advocacy arms, and influence over federal funders of research. For an example of such a hub see the Mental Health Commission of Canada (http://www.mentalhealth commission.ca). Such institutes can be highly effective in leveraging support for strategic responses to social problems, such as the "At Home" study of the Mental Health Commission of Canada, which is the largest study of the housing first model undertaken to date. Less clear is the potential for local responses to youth homelessness. For example, what might happen if an individual city set as a priority eradicating youth homelessness and developed an integrated response? Such approaches may hold more promise than waiting for coordinated provincial, state, or national responses which may bring us back to the Godotlike wait for prevention strategies to materialize just because we ask for them in discussion sections.

As much as this commentary might read like a rather bleak reflection of our collective responses to youth homelessness, I believe that there is an opportunity to catalyze attention and resources around this issue. Even though youth homelessness arguably has less media attention than it did ten years ago and resources are less available, the public and our policy makers are still troubled by the idea of young people being assaulted, selling their bodies, declining in health and dying in both our urban and rural settings. There are also many programs and services offering highly innovative and effective (at least understood in an anecdotal sense) strategies that address youth homelessness that are not being studied or propagated. If specific, tangible, and promising solutions can be offered, rather than simply reiterating accounts of risk that cultivate a collective helplessness, I have every confidence that financial and social resources will materialize.

\section{References}

Abbott, G. (1933). The child. American Journal of Sociology, 38, $880-888$.

Adams, G. R., Gullotta, T., \& Clancy, M. A. (1985). Homeless adolescents: A descriptive study of similarities and differences between runaways and throwaways. Adolescence, 20, 715-723.

Adams, G. R., \& Munro, G. (1979). Portrait of the North American runaway: A critical review. Journal of Youth and Adolescence, 8 , 359-373.

Buiso, G., \& Giove, C. (2011, December 3). None in the oven: Bump chump begger pregger for 13 months. New York Post. Accessed, December 14, 2011. http://www.nypost.com/p/news/local/none in_the_oven_z1UXVqwzjjtEUg0CragbOK.

Burnham, J. C. (1988). Paths into American culture: Psychology, medicine, and morals. Philadelphia: Temple University Press.

Burt, C. (1923). Delinquency and mental defect (II). British Journal of Medical Psychology, 3, 168-178.

Caplan, N., \& Nelson, S. D. (1973). On being useful: The nature and consequences of psychological research on social problems. American Psychologist, 28, 199-212.

Dadds, M., Braddock, D., Cuers, S., Elliott, A., \& Kelly, A. (1993). Personal and family distress in homeless adolescents. Соттиnity Mental Health Journal, 29, 413-422.

Fisher, R., Grant, P., \& Callahan, M. (1986). The potential role of theory in the training of applied social psychologists. Canadian Psychology, 27, 231-238.

Folks, H. (1900/1971). The care of destitute, neglected, and delinquent children. Arno: New York.

Furnald, G. G. (1912). The defective delinquent class differentiating tests. Journal of Insanity, 68, 523-594.

Gershenson, A. (1998, December 6). Portrait of the young as homeless. New York Times, p.2.

Gilpin, F. (1930). The runaway child: A case study. Journal of the American Academy of Political and Social Sciences, 149, 47-57.

Gladwell, M. (2002). The tipping point. New York, NY: Back Bay Books.

Jenkins, R. L. (1971). The runaway reaction. American Journal of Psychiatry, 128, 168-173.

Kidd, S. A. (2003). Street youth: Coping and interventions. Child and Adolescent Social Work Journal, 20, 235-261.

Kidd, S. A. (2007). Youth homelessness and social stigma. Journal of Youth and Adolescence, 36, 291-299.

Kidd, S. A., \& Davidson, L. (2007). You have to adapt because you have no other choice: The stories of strength and resilience of 208 homeless youth in New York City and Toronto. Journal of Community Psychology, 35, 219-238.

Kidd, S.A., \& McKenzie, K. Moving the mental health equity dialogue forward: The promise of a social entrepreneur 
framework. Administration and Policy in Mental Health and Mental Health Services Research. (in press).

Kidd, S. A., \& Scrimenti, K. (2004). The New Haven homeless count: Children and youth. Evaluation Review, 28, 325-341.

Kidd, S. A., \& Taub, B. G. (2004). A history of psychological research into the runaway phenomenon: From delinquent to street kid. Journal of Social Distress and the Homeless, 13, 327-344.

Leventhal, T. (1964). Inner control deficiencies in runaway children. Archives of General Psychiatry, 11, 170-176.

Levy, J. (1933). The homeless boys retreat. Mental Hygiene, 17, 369-373.

Libertoff, K. (1980). The runaway child in America: A social history. Journal of Family Issues, 1, 151-164.

Lindsay, E. W., Kurtz, D., Jarvis, S., Williams, N. R., \& Nackerud, L. (2000). How runaways and homeless youth navigate troubled waters: Personal strengths and resources. Child and Adolescent Social Work Journal, 17, 115-140.

Maclean, M. G., Embry, L. E., \& Cauce, A. M. (1999). Homeless adolescents' paths to separation from family: Comparison of family characteristics, psychological adjustment, and victimization. Journal of Community Psychology, 27, 179-187.

Martino, S. C., Tucker, J. S., Ryan, G., Wenzel, S. L., Golinelli, D., \& Munjas, B. (2011). Increased substance use and risky sexual behavior among migratory homeless youth: Exploring the role of social network composition. Journal of Youth and Adolescence, 40, 1634-1648.

McIver, J. (1927). The juvenile delinquent. Journal of the American Medical Association, 89, 1598-1600.

Mennel, R. M. (1973). Thorns and thistles: Juvenile delinquents in the United States 1825-1940. Hanover, NH: University Press of New England.

Minkler, M. (1999). Personal responsibility for health? A review of the arguments and the evidence at century's end. Health, Education, \& Behavior, 26, 121-141.

Molnar, B. E., Shade, S. B., Kral, A. H., Booth, R. E., \& Watters, J. K. (1998). Suicidal behavior and sexual/physical abuse among street youth. Child Abuse and Neglect, 22, 213-222.

New York Times. (1931, October 11). Four runaway boys are found in Harlem. New York Times, p. N3.

New York Times. (1932, November 13). 5,000 boys found adrift in the city. New York Times, p. 26.

New York Times. (1968, August 2). Runaway girls in East Village live on fear street. New York Times, p. 23.

New York Times. (1988, February 11). Runaways of the 80's: Victims of abuse. New York Times, p. C13.

Newcomb, F. F. (1933). Transient boys. Family, 14, 57-59.

Nisbett, R. E., \& Ross, L. (1980). Human inferences: Strategies and shortcomings in social judgment. Englewood Cliffs, NJ: Prentice-Hall.

O'Grady, B., \& Greene, C. (2003). A social and economic impact study of the Ontario safe streets act on Toronto squeegee workers. Online Journal of Justice Issues, 1(1), 1-8.

Outland, G. E. (1938). Determinants involved in boy transiency. Journal of Educational Sociology, 11, 360-372.

Pollio, D., Thompson, S., Toblas, L., Reid, D., \& Spitznagel, E. (2006). Longitudinal outcomes for youths receiving runaway/homeless shelter services. Journal of Youth and Adolescence, 35, 859-866.

Raz, J. (2009). The authority of law: Essays on law and morality. London: Oxford University.

Rew, L., \& Horner, S. D. (2003). Personal strengths of homeless adolescents living in a high-risk environment. Advances in Nursing Science, 26, 90-101.

Riemer, M. D. (1940). Runaway children. American Journal of Orthopsychiatry, 10, 522-527.
Ringwalt, C. L., Greene, J. M., \& Robertson, M. J. (1998). Familial backgrounds and risk behaviors of youth with throwaway experiences. Journal of Adolescence, 21, 421-452.

Robins, L. N., \& O'Neal, P. (1959). The adult prognosis for runaway children. Amercian Journal of OrthoPsychiatry, 29, 752-761.

Roy, É., Haley, N., Boudreau, J.-F., Leclerc, P., \& Boivin, J.-F. (2010). The challenge of understanding mortality changes among homeless youth. Journal of Urban Health, 87, 96-101.

Roy, E., Haley, N., Leclerc, P., Sochanski, B., Boudreau, J., \& Boivin, J. (2004). Mortality in a cohort of street youth in Montreal. Journal of the American Medical Association, 292, 569-574.

Sameroff, A. J. (2009). The transactional model of development: How children and contexts shape each other. Washington, DC: American Psychological Association.

Sampson, E. E. (1977). Psychology and the American ideal. Journal of Personality and Social Psychology, 35, 767-782.

Saul, M. (2002, August 9). Bloomberg says city failed suicide teen. New York Daily News. Accessed December 14, 2001. http:// articles.nydailynews.com/2002-08-09/news/18205623_1_mayorbloomberg-city-shelter-homeless-services-department.

Shaw, M., \& Dorling, D. (1998). Mortality among street youth in the UK. Lancet, 352, 743.

Slesnick, N., Bartle- Haring, S., Dashora, P., Kang, M., \& Aukward, E. (2008). Predictors of homelessness among street-living youth. Journal of Youth and Adolescence, 37, 465-474.

Slesnick, N., \& Kang, M. (2008). The impact of an integrated treatment on HIV risk behavior among homeless youth: A randomized controlled trial. Journal of Behavioral Medicine, 21, $45-59$.

Switzer, J. (2011, June 7). Squeegee kid beat driver, police say. National Post. Accessed December 14. http://news.nationalpost. com/2011/06/07/squeegee-kid-beat-driver-police-say/.

Tallack, D. (1991). Twentieth-century America: The intellectual and cultural context. Harlow, England: Longman Group.

Thomas, W. R., \& Gostwyck, C. H. G. (1925). Observations on delinquent mental defectives. Journal of Mental Science, 71, 41-47.

Tucker, J. S., Edelen, M. O., Ellickson, P. L., \& Klein, D. J. (2011). Running away from home: A longitudinal study of adolescent risk factors and young adult outcomes. Journal of Youth and Adolescence, 40, 507-518.

U.S. Conference of Mayors. (2010). Status report on hunger and homelessness. Washington, DC: City Policy Associates.

U.S. Department of Education. (1989). Report to Congress on final reports submitted by states in accordance with section $724(b)$ (3) of the Stewart B. McKinney Homeless Assistance Act. Washington, DC: Author.

Vreeman, R., \& Carroll, A. (2007). A systematic review of schoolbased strategies to prevent bullying. Archives of Pediatric and Adolescent Medicine, 161, 78-88.

Walsh, S. M., \& Donaldson, R. E. (2010). Invited commentary: National safe place: Meeting the immediate needs of runaway and homeless youth. Journal of Youth and Adolescence, 39, 437-445.

Watkins, T. H. (1993). The great depression. Boston, MA: Little, Brown \& Co.

Wattenberg, W. W. (1956). Boys who run away from home. Journal of Educational Psychology, 47, 335-343.

Weidensall, J. (1913). Criminology and delinquency. Psychological Bulletin, 10, 229-237.

Williams, N. R., Lindsey, E. W., Kurtz, D., \& Jarvis, S. (2001). From trauma to resiliency: Lessons from former runaway and homeless youth. Journal of Youth Studies, 4, 233-253. 


\section{Author Biography}

Sean Kidd is the Head of Psychological Services in the Toronto Centre for Addiction and Mental Health Schizophrenia Program and he is an Assistant Professor with the University of Toronto Department of Psychiatry. His research interests include examining resilience and community participation among marginalized persons and the effectiveness of psychiatric rehabilitation interventions. 